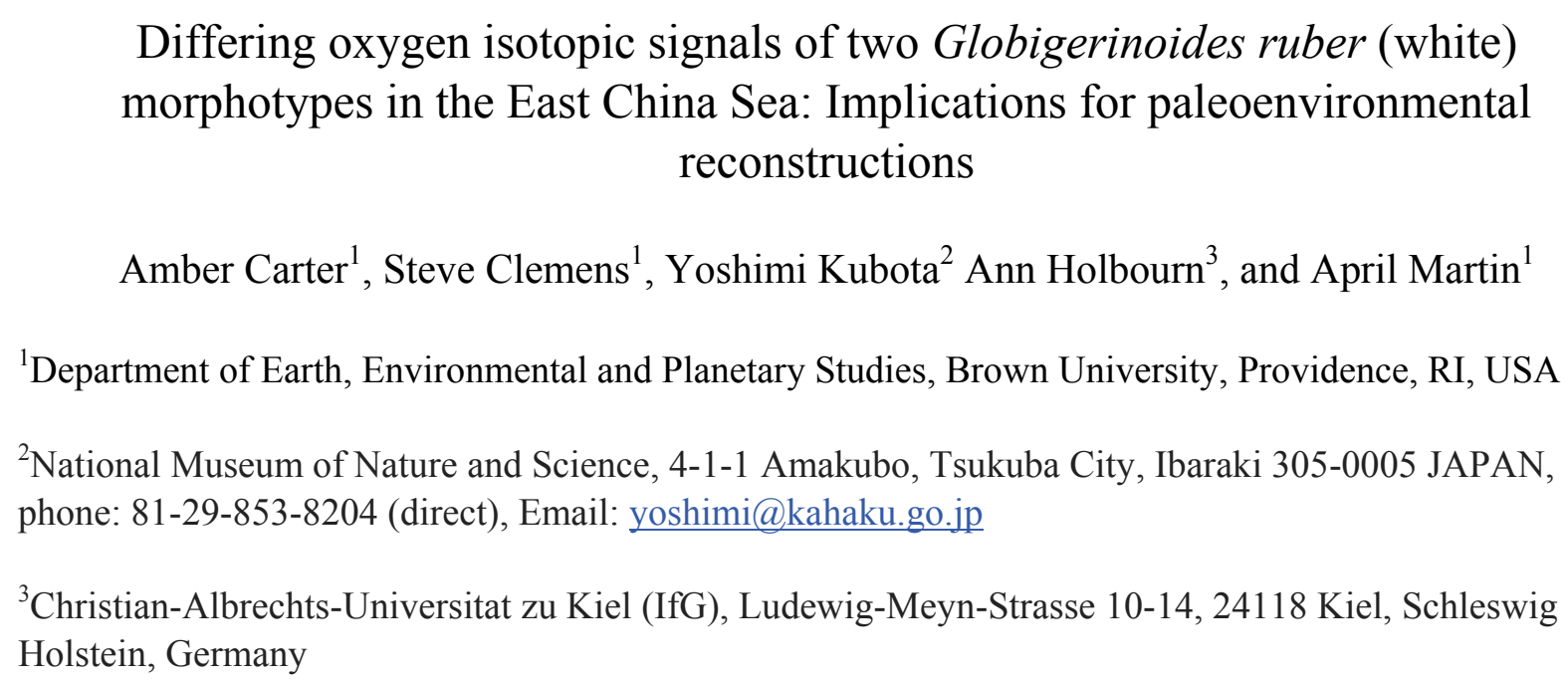

\section{Differing oxygen isotopic signals of two Globigerinoides ruber (white) morphotypes in the East China Sea: Implications for paleoenvironmental reconstructions}

The stable isotope composition of planktonic foraminifera, Globigerinoides ruber ( $G$. ruber), is a commonly used paleoenvironmental proxy. Globigerinoides ruber has two primary morphotypes, sensu stricto and sensu lato, which are differentiated by taxonomic criteria and, in some instances, stable isotopic values. Previous studies have reached differing conclusions surrounding the potential bias caused by the use of non-selective mixtures of morphotypes in paleoenvironmental reconstructions involving stable isotopes. Here, G ruber s.s. and G. ruber s.1. from five time intervals within the last $85 \mathrm{ka}$, were analyzed from IODP Site U1429 sediments in the East China Sea. The oxygen isotopic compositions of these two morphotypes show statistically significant differences within all five intervals, with smaller s.s. values relative to s.l. values. The largest differences $(0.77 \%$ o to $0.82 \%$ ) are observed during interglacials (Holocene and Marine Isotopic Stage 5.1) with smaller differences during Marine Isotopic Stage $3(0.45 \%$ o to $0.56 \%$ ) and the Last Glacial Maximum $(0.21 \%$ ). The isotopic offset between s.s. and s.l. is consistent with a deeper (colder) calcification depth of the s.l. morphotypes in the East China Sea. The decreased offset between the two morphotypes with increased glacial conditions may reflect decreased water column stratification during glacial intervals relative to interglacial intervals. According to these results, using a non-selective mixture of G. ruber morphotypes in paleoenvironmental reconstructions is inadvisable in this region. 


\section{INTRODUCTION}

The ubiquitous distribution of planktonic foraminifera in the world's oceans and their geochemistry makes them a powerful tool for paleoenvironmental reconstructions. The stable isotope composition of one species of planktonic foraminifera, Globigerinoides ruber (d'Orbigny, 1839), has been used in reconstructing ocean pH (e.g., Henehan et al. 2013) surface and subsurface seawater temperatures (e.g., Sadekov et al. 2009) as well as changes in the water

42 column structure during the Miocene to Pleistocene (e.g., Wang, 2000).

Globigerinoides ruber (white) has several morphotypes that differ from the original definition of the species G. ruber sensu stricto (s.s.) (e.g., Srinivasan et al. 1983). These morphotypes are generally referred to as G. ruber sensu lato (s.1.). A number of studies have investigated the potential for bias caused by the use of non-selective mixtures of these morphotypes in the geochemical analyses commonly used for paleoenvironmental reconstructions.

Studies in the Atlantic Ocean (Gulf of Mexico), eastern Indian Ocean, and the central tropical Pacific Ocean found that morphotypical variability has no statistically significant impact on the stable oxygen isotopic composition of G. ruber (Thirumalai et al. 2014, Mohtadi et al. 2009, and Lynch-Stieglitz et al. 2015) In contrast, other studies in the Atlantic Ocean (Gulf of Mexico), South China Sea and North Pacific found statistically significant differences between the stable isotopic compositions of the s.s. and s.1. morphotypes (Antonarakou et al. 2015, Kawahata, 2005; Löwemark et al., 2005; Steinke et al., 2005; Wang, 2000).

These differing conclusions imply regional/ocean basin variations or temporal variations in the geochemistry of G. ruber. The purpose of this study is to assess the morphological variations of $G$. ruber in the East China Sea, a marginal basin in the western Pacific. This site is currently being used to reconstruct changes in Yangtze River runoff using the isotopic composition of G. ruber. Understanding the extent to which s.s. and s.l. must be differentiated is crucial to accurately reconstruct the $\delta^{18} \mathrm{O}$ of sea water. Here, we assess the isotopic compositions 62 of G. ruber at five distinct time intervals; Marine Isotope Stage (MIS) 1 (Holocene), MIS 2 (full 63 glacial), MIS 3.1 (stadial and interstadial), MIS 3.3 (stadial and interstadial), and MIS 5.1 (full 64 interglacial). Each marine isotope stage represents distinct regional (and global) environmental 65 conditions. Understanding whether the isotopic compositions vary between morphotypes at this 
location and across these climatically distinct time intervals will help to further delineate the

67 geographic nature and potential causes of these differences.

\section{MATERIALS AND METHODS}

2.1 Location

The samples used for this study were obtained during Integrated Ocean Drilling Program

72 (IODP) Expedition 346 to the East China Sea (Figure 1). The three holes drilled at Site U1429

$73\left(31^{\circ} 37.04^{\prime} \mathrm{N}, 128^{\circ} 59.85^{\prime} \mathrm{E}, 732\right.$ meters below sea level) were used to produce a composite record of 181.4 meters in length. Our samples are all from within the upper 50 meters.

\subsection{Sample Selection}

The Globigerinoides ruber variants are defined using the taxonomic criteria described by Wang (2000). The s.s. morphotype has symmetrical, spherical chambers with a wide, higharched aperture (Figure 2A). The s.1. morphotype analyzed in this study has a more compact test with a compressed and flattened final chamber, and a relatively small aperture (Figure $2 \mathrm{~B}$ ). A

81 third morphotype, informally designated as sensu lato extreme (s.1.e.) was differentiated based on

82 its extremely flattened and asymmetrical final chamber and very small aperture (Figure 2C).

Structure in the full (180 meter) planktonic and benthic $\delta^{18} \mathrm{O}$ record (not shown in Figure

3) allowed us to confidently identify all marine isotopic stages (MIS; Prell et al., 1986) spanning the past 380 kybp. Figure 3 shows our sample locations in this context; samples taken from 0.78 - 1.98 meters are from MIS 1 (Holocene), 12.14-14.54 meters from MIS 2 (glacial), 17.90 22.10 meters from MIS 3.1 (stadial and interstadial), 26.91 - 29.01 meters from MIS 3.3 (stadial and interstadial), and lastly, samples from 45.10 - 45.55 meters from MIS 5.1 (interglacial).

\subsection{Sample Preparation and Stable Isotope Analyses}

Sediment samples were wet sieved to remove the fine fraction $(<63 \mu \mathrm{m})$, dried overnight

93 in a $40^{\circ} \mathrm{C}$ oven, then dry sieved before isolating the s.s., s.1., and s.l.e. specimens ( $250-355 \mu \mathrm{m}$

94 size fraction) using a binocular microscope. The number of specimens in each sample varied

95 from 3 to 52 with an average of 20 specimens in each sample. Samples with 15 or fewer

96 specimens were cleaned in ethanol and run whole through the mass spectrometer. Samples with 
97 greater than 15 specimens were cleaned in ethanol, crushed, homogenized, and subsampled ( $\sim 80$ 98 micrograms of $\mathrm{CaCO}_{3}$ ) prior to running on the mass spectrometer. A total of 96 measurements 99 (s.s., s.l., and s.l.e.) were performed at Brown University using a Finnigan MAT 252 coupled to 100 Kiel III Carbonate Device. The machine precision is $\pm 0.06 \%$ o $(1 \sigma)$ for $\delta^{18} \mathrm{O}$ measured on the in101 house standards (Carrara Marble and Brown Yule Marble). The stable oxygen isotope results 102 (Table 1) are reported relative to the Vienna Pee Dee Belemnite (VPDB) standard. One s.s.

103 outlier $\left(\delta^{18} \mathrm{O}\right.$ at $\left.14.24 \mathrm{~m}\right)$ was rejected from the statistical analysis due to insufficient voltage (not 104 enough gas generated to achieve relatable counting statistics).

105

\subsection{Statistical Evaluation}

A null hypothesis test was employed to test if the differences between the isotopic compositions of the three morphotypes are statistically significant. The null hypothesis, morphological variability has no effect on G. ruber geochemistry, was tested for samples from 110 each time interval using Welch's unpaired T Test (for normally distributed data) and the 111 unpaired Mann Whitney Wilcoxon Ranksum Test (for nonparametric data) following the 112 statistical methodology of Thirumalai et al. (2014). Neither of these tests assume equal sample 113 size or variance. All populations were found to be normally distributed based on the Shapiro114 Wilk test, except for the $\delta^{18} \mathrm{O}$ MIS 2 (glacial) samples. All measurements were assessed at the $11595 \%$ confidence interval $(\mathrm{p}<0.05)$. Hence, if the reported $\mathrm{p}$ value is greater than this threshold, 116 the null hypothesis cannot be rejected. If the reported $\mathrm{p}$ value is less than this threshold, the null

117 hypothesis must be rejected. These analyses were done twice, first comparing the s.l. and s.l.e. 118 variants, then comparing s.s. to the combined s.l. and s.l.e. variants. The results of these 119 statistical analyses are reported in Table 2.

122 We gathered temperature and salinity data from the Japan Oceanographic Data Center for 123 the location of Site U1429. Using the Horikawa et al. (2015) equation, we converted salinity to 124 the oxygen isotopic composition of seawater (Eq.1). This equation was derived from data 125 collected from the Yellow Sea- East China Sea and Kuroshio sites which are in close proximity 126 to Site U1429. The Bemis et al. (1998) highlight equation was used to convert the temperature 127 and $\delta^{18} \mathrm{O}$ of seawater to predicted $\delta^{18} \mathrm{O}$ of calcite (Eq. 2). This $\delta^{18} \mathrm{O}_{\mathrm{C}}-$ temperature equation was 
128 determined from culturing experiments of planktonic foraminifera species grown under high-

129 light conditions. These equations were employed to replicate the methodology used by Kubota et

130 al. (2010) in the northern East China Sea. Similar methodologies were also used by Khider et al.

131 (2011) and Schmidt (1999).

132

$133 \quad \delta^{18} \mathrm{O}_{\mathrm{sw}}=-7.74( \pm 0.4)+0.23( \pm 0.1) \mathrm{x}$ salinity

(Equation 1)

134

$135 \mathrm{~T}\left({ }^{\circ} \mathrm{C}\right)=14.9-4.8\left(\delta^{18} \mathrm{O}_{\mathrm{C}}-\left(\delta^{18} \mathrm{O}_{\mathrm{sw}}-0.27 \%\right)\right)$

(Equation 2)

\section{RESULTS}

138 When analyzing the stable oxygen isotopic oxygen results we found that, across all time 139 intervals, the null hypothesis could not be rejected when comparing the s.l. and s.l.e.

140 morphotypes. In other words, there is no statistically significant difference between the oxygen

141 isotope values of the s.l. and s.l.e. morphotypes. On this basis, the s.l. and s.l.e. morphotypes

142 were combined and compared to s.s., finding that the null hypothesis must be rejected, i.e. there

143 is a statistically significant difference, for all time intervals (Table 2). Wang (2000) also

144 combined the s.l. and s.l.e. sub-groups (referred to as "low and high trochospires") after finding

145 they did not show significant differences in their isotopic signals. Generally, G. ruber s.s. shows

146 lighter $\delta^{18} \mathrm{O}$ values compared to s.1. (Figure 4).

\section{DISCUSSION}

Three possible mechanisms could explain why the s.s. and s.l. morphotypes show consistently different oxygen isotopic compositions: different seasonal production rates, different calcifying depths, or vital effects.

\subsection{Seasonal Production Rate}

If seasonal preference is the underlying factor behind this difference, we would expect one morphotype to be more abundant than the other in a particular season, since the heavier $\delta^{18} \mathrm{O}$

157 values would indicate that s.l. calcifies in colder water while s.s. calcifies in warmer waters 158 (Berger, 1970; Hecht, 1972, Kuroyanagi and Kawahata, 2004). Sediment trap data can be used to 
159 quantify the monthly production of each morphotype. In the previous studies of G. ruber

160 morphotypes done by Thirumalai et al. (2014) and Wang (2000) in the Gulf of Mexico and the

161 Pacific Ocean, sediment trap data was used to rule out a seasonal preference. Other studies of

162 these morphotypes either did not have sediment trap data or did not report the flux of the s.s. and

163 s.l. morphotypes separately (Kawahata, 2005; Mohtadi et al., 2009; Steinke et al., 2005). No

164 sediment trap data comparing s.s. to s.1. are available for the East China Sea proper.

165 Wang et al. (1999) used ten well-dated sediment records with millennial to bidecadal

166 time resolution over the last 220,000 years to conclude that the Last Glacial Maximum had

167 greater seasonality. If these morphotypes have different seasonal production rates, we would

168 expect the offset between their isotopic compositions to increase during times of increased

169 seasonality. The isotopic difference between s.s. and s.l. is smallest during glacial periods and

170 largest during interglacial periods (Table 3). Hence, it is unlikely that a seasonal preference is the

171 mechanism controlling the isotopic composition of these morphotypes. However, these findings

172 by Wang et al. (1999) may be location specific and may not necessarily be applicable to the East

173 China Sea.

174

175 4.2 Calcification Depth and the Depth of the Mixed Layer

176 If these morphotypes have different calcifying depths, we would expect the water column

177 profiles of temperature and salinity to corroborate the measured $\delta^{18} \mathrm{O}$ values. In the western Gulf

178 of Mexico, Thirumalai et al. (2014) use a model to predict the isotopic composition of G. ruber

179 shells as a function of season and calcification depth. They found that s.s. and s.1. have similar

180 calcifying depths corroborating their conclusion that s.s. and s.l. are statistically

181 indistinguishable. Wang (2000) and Löwemark et al. (2005) came to the opposite conclusion in

182 the South China Sea. Using in situ water column profiles, they found a $2-3^{\circ} \mathrm{C}$ temperature

183 decrease and a $0.20-0.25$ salinity increase between the surface (0-30 meters) and the subsurface

184 waters (30-50 meters). This is consistent with their observed 0.4\% average offset between s.s.

185 and s.l. Wang (2000) and Löwemark et al. (2005) inferred that in the South China Sea s.s.

186 inhabits the upper 30 meters of the water column while s.l. lives between 30 and 50 meters. In

187 the eastern Gulf of Mexico, Antonarakou et al. (2015) also found that s.s. inhabits the upper

$188 \sim 30 \mathrm{~m}$ of the water column while s.1. inhabits depths below $30 \mathrm{~m}$. 
In the East China Sea, very close to Site U1429, Horikawa et al. (2015) used measured

190 temperature and salinity data to simulate the oxygen isotopic composition of planktonic

191 foraminifera as a function of depth (Eq.1) using the Bemis et al. (1998) calcite equilibrium

192 equation (Eq.2). Applying the same approach to compare the predicted isotopic values with our

193 observed isotopic data, we found that the average Holocene isotopic compositions for s.s. and s.l.

$194(-2.39 \%$ and $-1.62 \%$ respectively, Table 3$)$ occur at depths of about 10 meters and 60 meters

195 (Figure 5). These results are consistent with the hypothesis that calcifying depth may account for 196 the isotopic offset between the s.s. and s.l. morphotypes.

The East China Sea is a very dynamic region of the ocean. Water column dynamics are

198 impacted by seasonally varying atmospheric conditions such as heating, cooling, and wind stress

199 (Chu et al. 2005) as well as changes in the Kuroshio Current (Andres et al. 2015). Strong

200 regional variation in atmospheric and oceanic conditions may account for differences in depth

201 habitat inferred for our East China Sea data relative to that inferred for the South China Sea

202 (Wang 2000; Löwemark et al., 2005). Regional differences are evident in the extent of isotopic

203 offset observed among s.s. and s.l. morphotypes (Table 4). Previous studies in the South China

204 Sea found isotopic offsets between $0.27 \%$ and $0.5 \%$, while in the East China Sea we found

205 offsets are large as $0.77 \%$ (Table 3). The general trend in the North Pacific marginal basins

206 evaluated to date, appears to be a north to south decrease in the isotopic offset between

207 morphotypes (Figure 1, Table 4). This north to south gradient parallels the north to south

208 deepening of the mixed layer in the summer months when the flux of G. ruber is the greatest

209 (Figure 6) (Xu et al. 2005). In the summer months, runoff from the Yangtze River causes

210 increased water column stratification at Site U1429 (Site 1 on Figure 6), while the sites further

211 south are less affected (Hao et al. 2012). We hypothesize that the s.s. depth of calcification is

212 controlled by the depth of the seasonal thermocline while the s.l. depth of calcification is

213 controlled by the permanent thermocline. Regions with increased stratification have greater

214 differences between their seasonal and permanent thermocline depths resulting in a greater $\delta^{18} \mathrm{O}$

215 offset between s.s. and s.l. Sites further south are less affected by the summer monsoon runoff,

216 resulting in diminishing offsets between their s.s. and s.1. isotopic values.

217

$218 \quad 4.3$ Vital Effects 
The s.s and s.1. morphotypes have been identified as distinct genotypes of G. ruber

220 (Aurahs et al. 2011, Kuroyanagi et al. 2008), consistent with differing isotopic signals.

221 Planktonic foraminifera may not calcify in oxygen isotopic equilibrium with the surrounding

222 seawater, a phenomenon known as 'vital effects'. The photosynthetic activity of algal symbionts

223 living in the shells of foraminifera alters their calcification rate (Lee et al. 1987, Nooijer et al.

224 2009), causing the G. ruber $\delta^{18} \mathrm{O}$ of calcite and seawater to differ by about \pm 0.0 to $-1.0 \%$

225 (Niebler et al. 1999). We cannot assess if or how these algal symbionts affect the morphotypes of

226 G. ruber or if that difference is a reflection of their differing biology, so we cannot exclude the

227 possibility that vital effects differ among these morphotypes, contributing to their isotopic offset.

228

4.4 Extent of Glaciation and Changes in the Thermocline

Our results indicate that the extent of glaciation is strongly coupled to the oxygen isotopic

231 offset of the s.s. and s.1. morphotypes (Figure 7). Wang (2000), Kawahata (2005), and

232 Antonarakou (2015) also observed this coupling in their studies of the South China Sea,

233 Northern Pacific, and eastern Gulf of Mexico respectively. In glacial periods, the water column

234 is likely to be less stratified due to colder air temperatures and increased monsoonal wind

235 mixing, driving the seasonal thermocline deeper (Wang, 2000). This results in the permanent and

236 seasonal thermoclines being closer together and the s.s. and s.1. morphotypes having closer $\delta^{18} \mathrm{O}$

237 values. In interglacial periods, increased runoff drives the seasonal thermocline to shallower

238 depths while the permanent thermocline remains unchanged, resulting in a larger isotopic offset

239 between s.s. and s.1.

240 Antonarakou (2015) in the eastern Gulf of Mexico also attributes the fluctuations in

241 isotopic offsets to climatic changes, yet found the opposite correlation. Their maximum oxygen

242 isotopic offset corresponds to cold events when the mixed layer is shallowest while the minimum

243 offset corresponds to warm events. Clearly, how water column dynamics respond to climatic

244 events is location specific, but it is evident that the depth of the thermocline is coupled to the

245 extent of glaciation.

2474.5 Isotopic Offset and Changing Climatic Conditions

248 The extent of changing climatic conditions appears to influence the detection of an

249 isotopic offset. When analyzing data across glacial and interglacial boundary conditions the 
oxygen isotopic offset between the s.s. and s.l. morphotypes becomes evident. This study, along

251 with Antonarakou et al. 2015, analyzed data from the last glacial event through the Holocene and

252 found a statistically significant difference between the s.s. and s.l. morphotypes. While studies

253 that focused on modern data found differing degrees of isotopic offsets that vary regionally

254 (Table 4).

This may explain why two studies in the Gulf of Mexico found differing results. When looking at modern data, Thirumalai et al. (2014) in the western Gulf of Mexico found no isotopic

257 difference between these morphotypes, while Antonarakou et al. (2015) in the eastern GOM

258 found minor isotopic differences when analyzing the same time frame. When Antonarakou et al.

259 (2015) looked through the late glacial, the isotopic differences reached their maximum values.

260 We hypothesize that the depth habitat of G. ruber morphotypes is influenced by the depth

261 of the mixed layer. Changes in the mixed layer depth are better expressed across glacial and

262 interglacial boundary conditions, and thus more easily detectable.

\section{CONCLUSION}

This study of the East China Sea as well as five others throughout the Atlantic and Pacific Oceans (Antonarakou 2015, Kawahata, 2005; Löwemark et al., 2005; Steinke et al., 2005; Wang 2000) conclude that morphological variations of the G. ruber species result in different isotope compositions. These isotopic differences are most evident when analyzing data over glacial/interglacial conditions. The correlation between our measured Holocene oxygen isotopic

270 compositions and the predicted composition within the water column indicates that the observed 271 isotopic offset is consistent with the morphotypes occupying different calcification depths. This

272 hypothesis is supported by the downcore oxygen isotopic compositions having a smaller offset in 273 the glacial period, when the water column in less stratified, and a larger offset in the interglacial

274 periods, reflecting a more stratified water column. Regionally varying water column

275 stratification may also explain the difference in regional calcification depths in the Holocene, as

276 well. Using a non-selective mixture of morphotypes invites error and possible misinterpretations

277 in paleoenvironmental reconstructions if the region has not been previously assessed for potential

278 differences in morphotype calcification. On the other hand, understanding how the oxygen

279 isotopic composition of s.s. and s.l. relate to the spatial and temporal stratification of the modern 280 water column could lead to a useful means to reconstruct past changes in ocean stratification. 
ACKNOWLEDGEMENTS

283 The authors would like to thank all of the undergraduate students who worked tirelessly on

284 processing these samples. This research used samples and/or data provided by the Integrated

285 Ocean Drilling Program (IODP). Funding for this research was provided by the Ocean Sciences

286 Grant OCE 1435266 through the National Science Foundation.

\section{REFERENCES}

Andres, M., S. Jan, T. Sanford, V. Mensah, L. Centurioni, and J. Book. 2015. Mean structure and

Antonarakou, A., G. Kontakiotis, P.G. Mortyn, H. Drinia, M. Sprovieri, E. Besiou, and E. variability of the Kuroshio from northeastern Taiwan to southwestern Japan. Oceanography 28(4):84-95, http://dx.doi.org/10.5670/oceanog.2015.84. Tripsanas. "Biotic and Geochemical Responses of G. ruber morphotypes to Upper Water Column Variations during the Last Deglaciation, Gulf of Mexico." Geochimica et Cosmochimica Acta 170 (2015): 69-93.

Aurahs, R., Y. Treis, K. Darling, and M. Kucera. "A Revised Taxonomic and Phylogenetic Concept for the Planktonic Foraminifer Species Globigerinoides ruber Based on Molecular and Morphometric Evidence." Marine Micropaleontology 79.1-2 (2011): 1-14. Elsevier, Apr. 2011.

Bemis, B., H. Spero, J. Bijma, and D. Lea. "Reevaluation of the Oxygen Isotopic Composition of Planktonic Foraminifera: Experimental Results and Revised Paleotemperature Equations." Paleoceanography 13.2 (1998): 150-60. 26 Feb. 2016.

Berger, W. "Planktonic Foraminifera: Differential Production and Expatriation off Baja California." Limnology and Oceanography 15.2 (1970): 183-204. 
Chu, P., C. Yuchun, and A. Kuninaka. "Seasonal Variability of the Yellow Sea/East China Sea Surface Fluxes and Thermohaline Structure." Adv. Atmos. Sci. Advances in Atmospheric Sciences 22.1 (2005): 1-20.

Coleman, M., and S. Chisholm. "Ecosystem-specific Selection Pressures Revealed through Comparative Population Genomics." Proceedings of the National Academy of Sciences 107.43 (2010): 18634-8639.

d'Orbigny, A. in Histoire physique, politique et naturelle de l'île de Cuba (La Sagra, de, R.) 1224 (Bertrand, 1839).

Hao, Jiajia, Yongli Chen, Fan Wang, and Pengfei Lin. "Seasonal Thermocline in the China Seas and Northwestern Pacific Ocean." Journal of Geophysical Research: Oceans 117.C2 (2012): n. pag.

Hecht, A., and S. Savin. "Phenotypic Variation and Oxygen Isotope Ratios in Recent Planktonic Foraminifera." The Journal of Foraminiferal Research 2.2 (1972): 55-67.

Henehan, M., J. Rae, G. Foster, J. Erez, K. Prentice, M. Kucera, H. Bostock, M. Martínez-Botí, J. Milton, P. Wilson, B. Marshall, and T. Elliott. "Calibration of the Boron Isotope Proxy in the Planktonic Foraminifera Globigerinoides ruber for Use in Palaeo-CO2 Reconstruction." Earth and Planetary Science Letters 364 (2013): 111-22.

Horikawa, K., T. Kodaira, J. Zhang, and M. Murayama. " $\delta 180$ sw Estimate for Globigerinoides ruber from Core-top Sediments in the East China Sea." Progress in Earth and Planetary Science Prog. in Earth and Planet. Sci. 2.1 (2015): n. pag. 22 Feb. 2016.

Ji, H., and Y. Jiang. "Carbon Flux and C, S Isotopic Characteristics of River Waters from a Karstic and a Granitic Terrain in the Yangtze River System." Journal of Asian Earth Sciences 57 (2012): 38-53.

Kawahata, H. "Stable Isotopic Composition of Two Morphotypes of Globigerinoides ruber (white) in the Subtropical Gyre in the North Pacific." Paleontological Research 9.1 (2005): 27-35. 
334 Khider, D., L. D. Stott, J. Emile-Geay, R. Thunell, and D. E. Hammond. "Assessing E1 Niño Southern Oscillation Variability during the past Millennium." Paleoceanography 26.3 (2011): n. pag.

Kubota, Yoshimi, Katsunori Kimoto, Ryuji Tada, Hirokuni Oda, Yusuke Yokoyama, and Deglaciation Based on $\mathrm{Mg} / \mathrm{Ca}$ and Oxygen Isotope of Planktic Foraminifera in the Northern East China Sea." Paleoceanography 25.4 (2010): n. pag.

Kuroyanagi, A., and H. Kawahata. "Vertical Distribution of Living Planktonic Foraminifera in the Seas around Japan." Marine Micropaleontology 53.1-2 (2004): 173-96.

Kuroyanagi, A., Tsuchiya, M., Kawahata, H., Kitazato, H. (2008) The occurrence of two genotypes of the planktonic foraminifer Globigerinoides ruber (white) and paleoenvironmental implications. Marine Micropaleontology, Vol. 68, pp. 236-243.

Lee, J., and P. Hallock. "Algal Symbiosis as the Driving Force in the Evolution of Larger Foraminifera." Ann NY Acad Sci Annals of the New York Academy of Sciences 503.1 Endocytobiolo (1987): 330-47.

Lynch-Stieglitz, Jean, P. Polissar, A. Jacobel, S. Hovan, R. Pockalny, M. Lyle, R. Murray, A. Ravelo, S. Bova, A. Dunlea, H. Ford, J. Hertzberg, C. Wertman, A. Maloney, J. Shackford, K. Wejnert, and R. Xie. "Glacial-interglacial Changes in Central Tropical Pacific Surface Seawater Property Gradients." Paleoceanography 30.5 (2015): 423-38.

Löwemark, L., W. Hong, T. Yui, and G. Hung. "A Test of Different Factors Influencing the Isotopic Signal of Planktonic Foraminifera in Surface Sediments from the Northern South China Sea." Marine Micropaleontology 55.1-2 (2005): 49-62.

Mohtadi, M., S. Steinke, J. Groeneveld, H. Fink, T. Rixen, D. Hebbeln, B. Donner, and B. Herunadi. "Low-latitude Control on Seasonal and Interannual Changes in Planktonic Foraminiferal Flux and Shell Geochemistry off South Java: A Sediment Trap Study." Paleoceanography 24.1 (2009): n. pag. 
Nooijer, L., T. Toyofuku, and H. Kitazato. "Foraminifera Promote Calcification by Elevating Their Intracellular pH." Proceedings of the National Academy of Sciences 106.36 (2009):

Numberger, L., C. Hemleben, R. Hoffmann, A. Mackensen, H. Schulz, J. Wunderlich, and M. 15374-5378.

Kucera. "Habitats, Abundance Patterns and Isotopic Signals of Morphotypes of the Planktonic Foraminifer Globigerinoides ruber (d'Orbigny) in the Eastern Mediterranean Sea since the Marine Isotopic Stage 12." Marine Micropaleontology 73.1-2 (2009): 90104.

Prell, W., J. Imbrie, D. Martinson, J. Morley, N. Pisias, N. Shackleton, and H. Streeter. "Graphic Correlation of Oxygen Isotope Stratigraphy Application to the Late Quaternary." Paleoceanography 1.2 (1986): 137-62.

Sadekov, A., S. Eggins, P. Deckker, U. Ninnemann, W. Kuhnt, and F. Bassinot. "Surface and Subsurface Seawater Temperature Reconstruction Using Mg/Ca Microanalysis of Planktonic Foraminifera Globigerinoides ruber, Globigerinoides sacculifer, and Pulleniatina obliquiloculata." Paleoceanography 24.3 (2009): n. pag.

Schmidt, G. "Forward Modeling of Carbonate Proxy Data from Planktonic Foraminifera Using Oxygen Isotope Tracers in a Global Ocean Model." Paleoceanography 14.4 (1999): 482 97.

Srinivasan, M., and J. Kennett. "The Oligocene-Miocene Boundary in the South Pacific." Geol Soc America Bull Geological Society of America Bulletin 94.6 (1983): 798.

Steinke, S., H. Chiu, P. Yu, C. Shen, L. Löwemark, H. Mii, and M. Chen. "Mg/Ca Ratios of Two Globigerinoides ruber (white) Morphotypes: Implications for Reconstructing past Tropical/subtropical Surface Water Conditions." Geochemistry, Geophysics, Geosystems Geochem. Geophys. Geosyst. 6.11 (2005): n. pag.

Thirumalai, K., J. Richey, T. Quinn, and R. Poore. "Globigerinoides ruber Morphotypes in the Gulf of Mexico: A Test of Null Hypothesis." Sci. Rep. Scientific Reports 4 (2014): n. pag. 
386 Wang, L. "Isotopic Signals in Two Morphotypes of Globigerinoides ruber (white) from the 387 South China Sea: Implications for Monsoon Climate Change during the Last Glacial 388 Cycle."Palaeogeography, Palaeoclimatology, Palaeoecology 161.3-4 (2000): 381-94.

389 Wang, L., M. Sarnthein, H. Erlenkeuser, J. Grimalt, P. Grootes, S. Heilig, E. Ivanova, M. Kienast, C. Pelejero, and U. Pflaumann. "East Asian Monsoon Climate during the Late

393 Xu, Xuedong, Makoto Yamasaki, Motoyoshi Oda, and Makio C. Honda. "Comparison of 394 Seasonal Flux Variations of Planktonic Foraminifera in Sediment Traps on Both Sides of the Ryukyu Islands, Japan." Marine Micropaleontology 58.1 (2005): 45-55. 


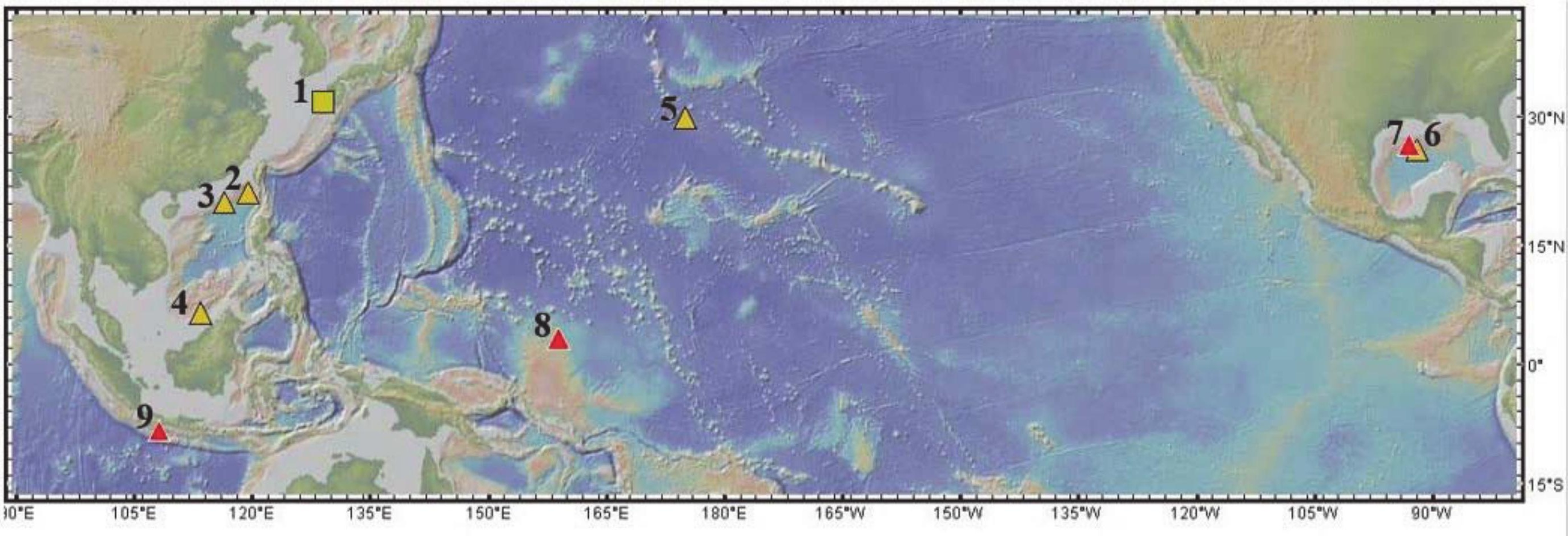



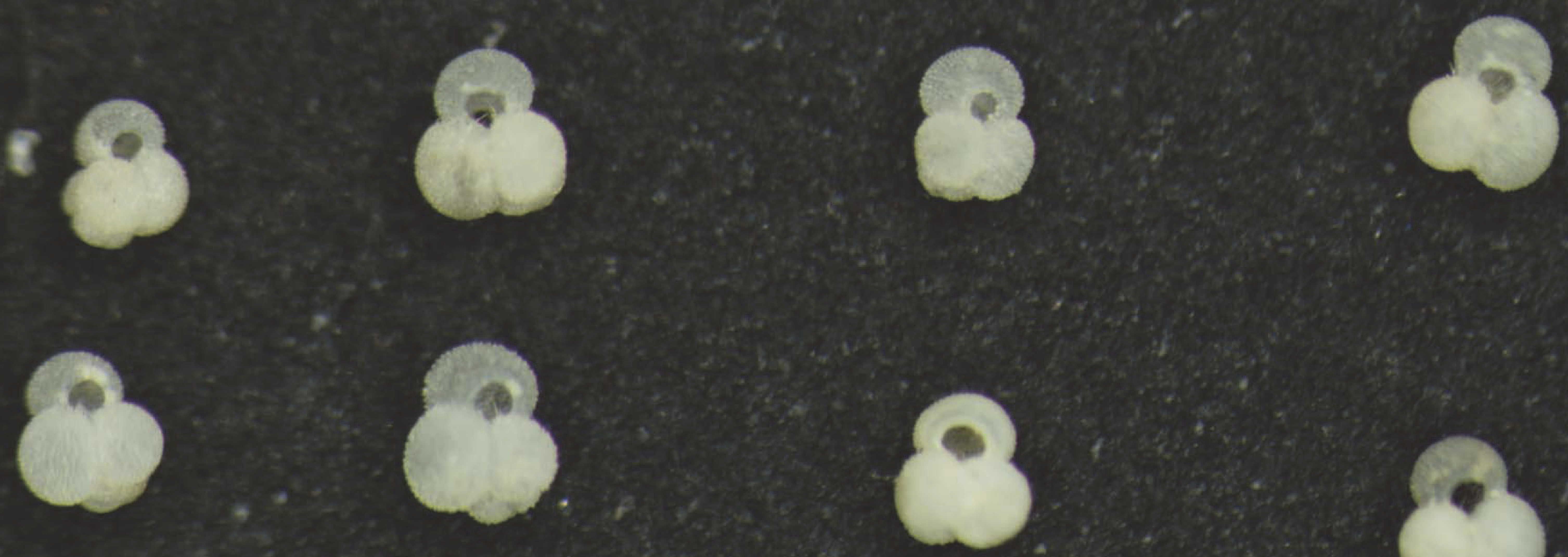

8 

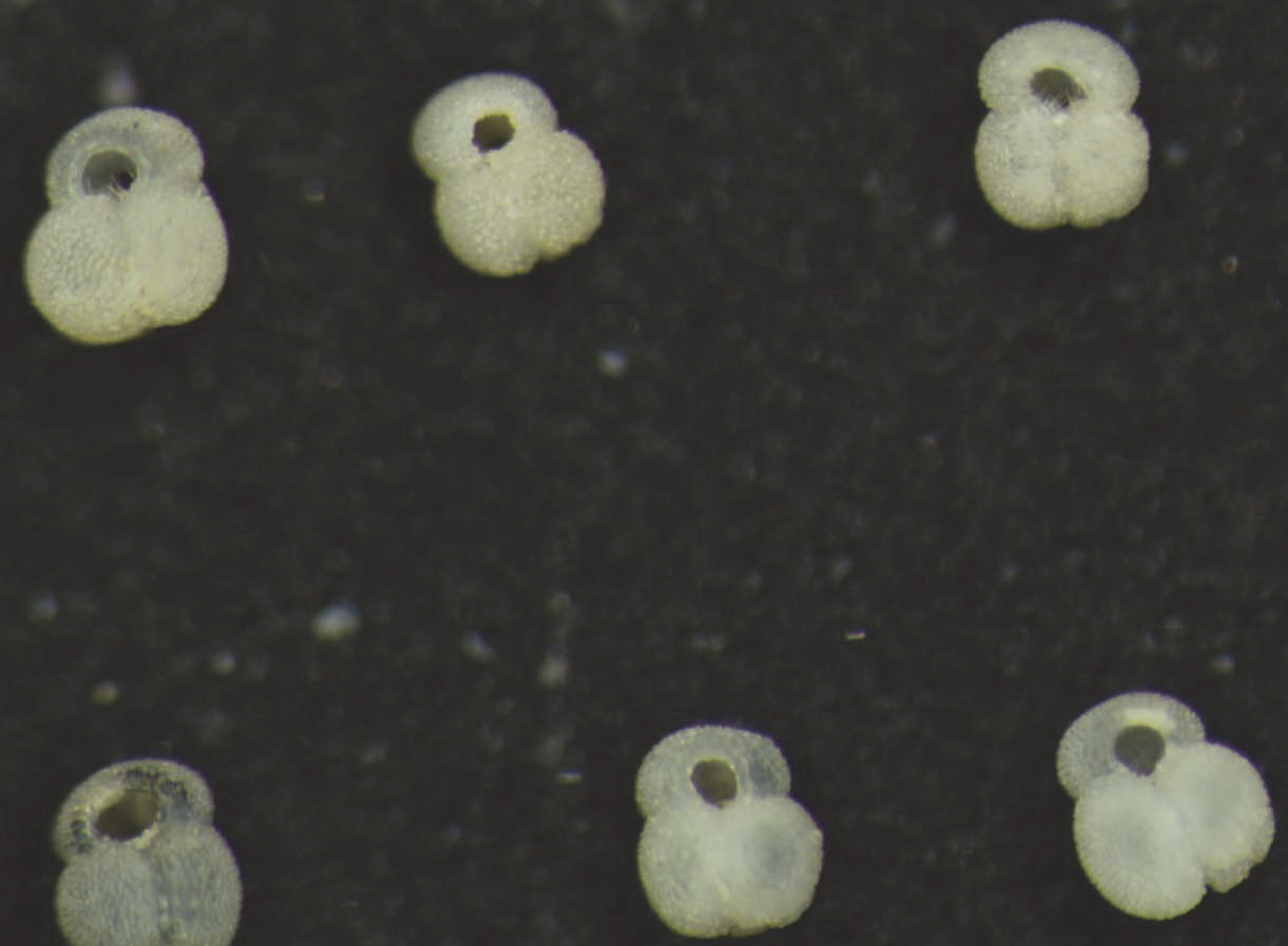

Creation Time: 10/30/2015 11:45:22 AM 


\section{C}
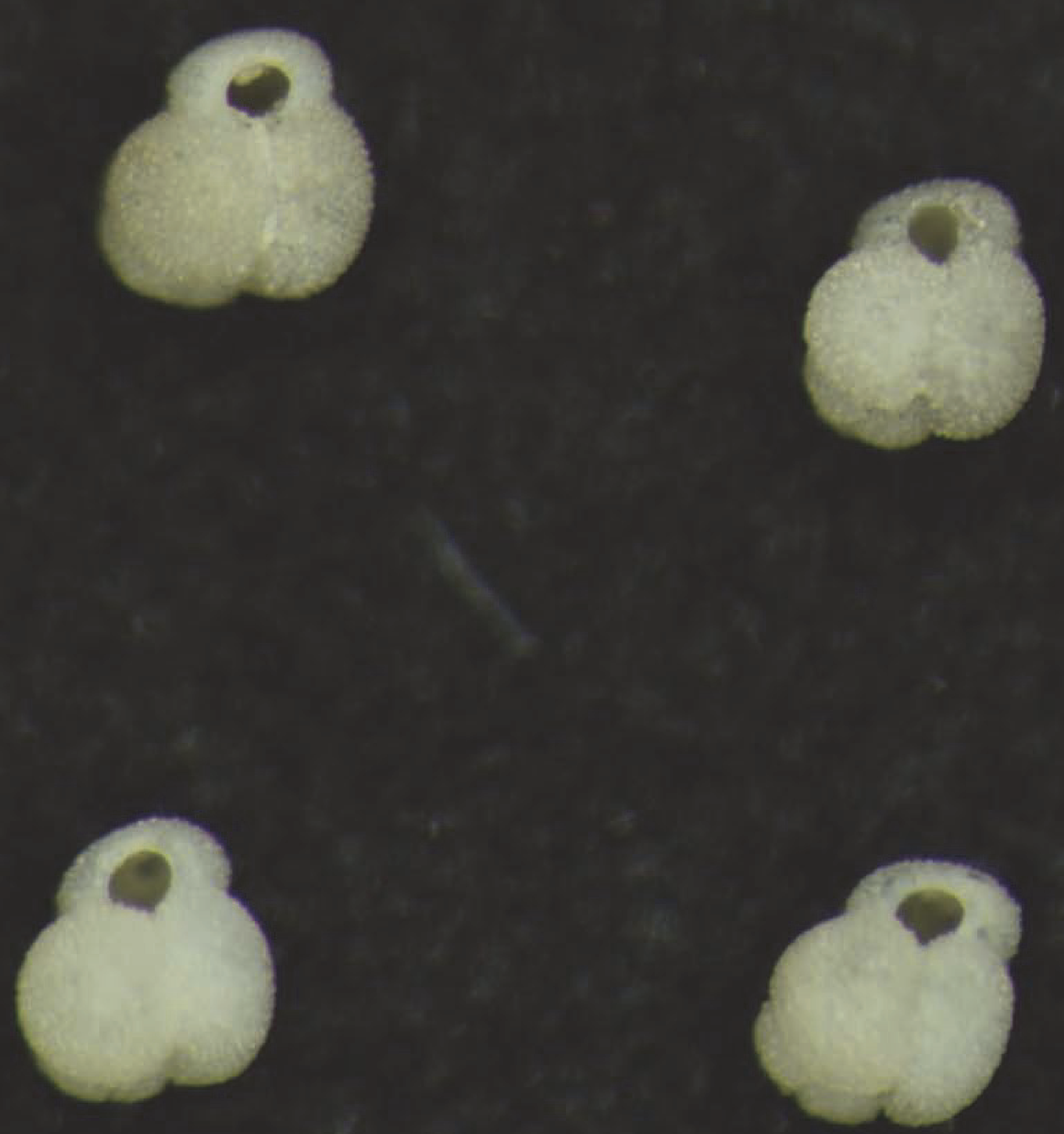


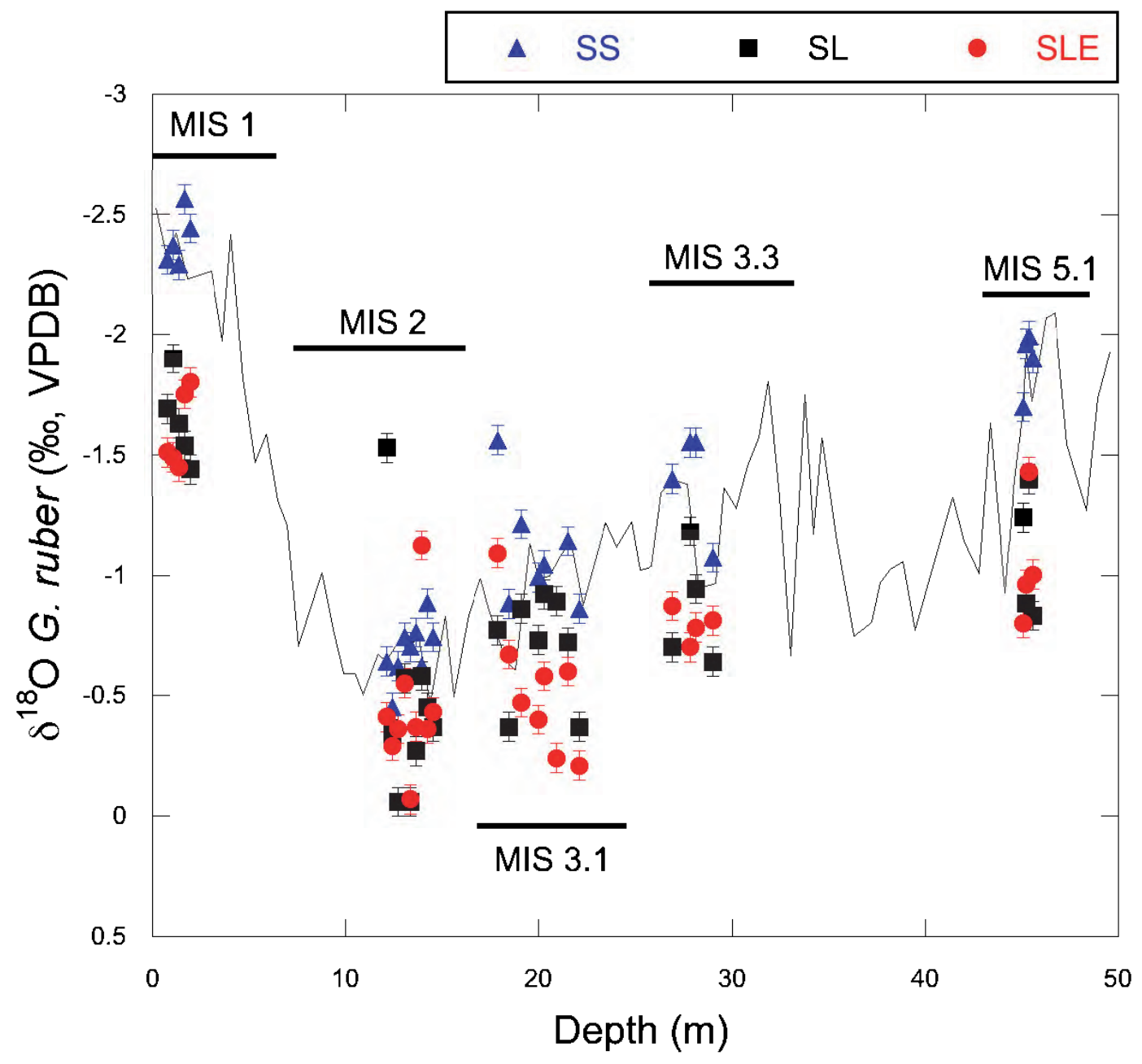




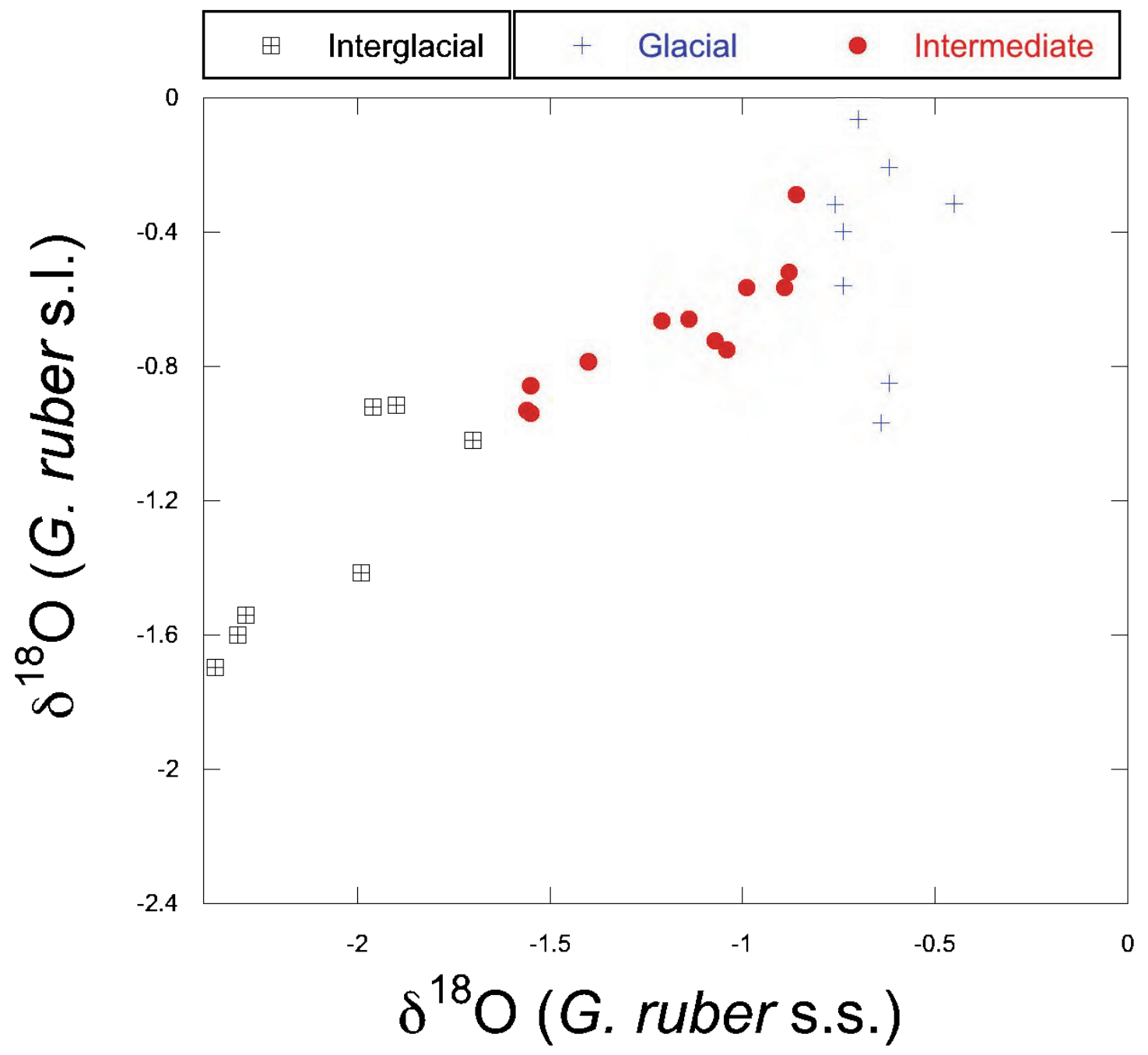




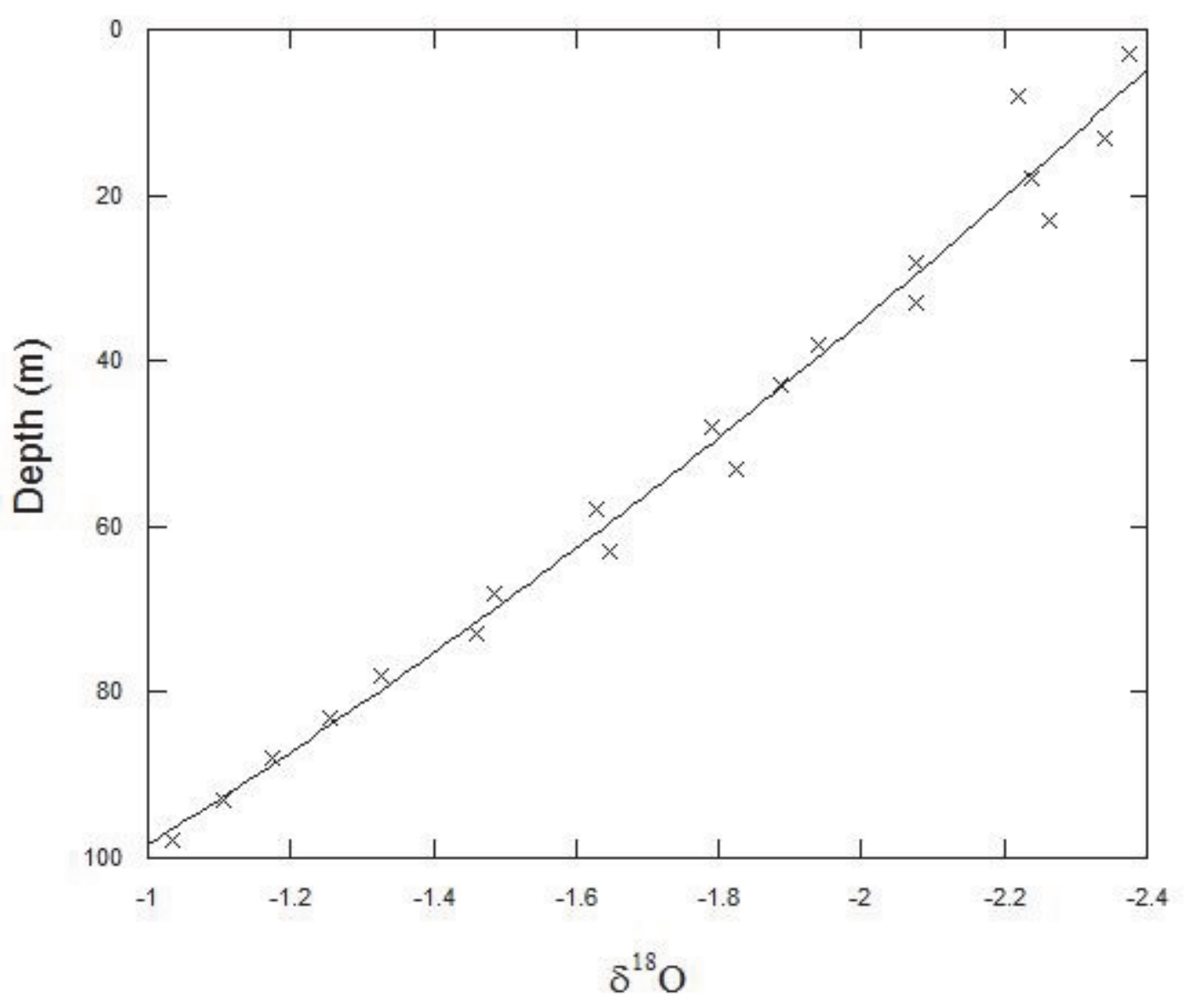


$y=-0.1606+0.28762 x \quad R=0.80245$

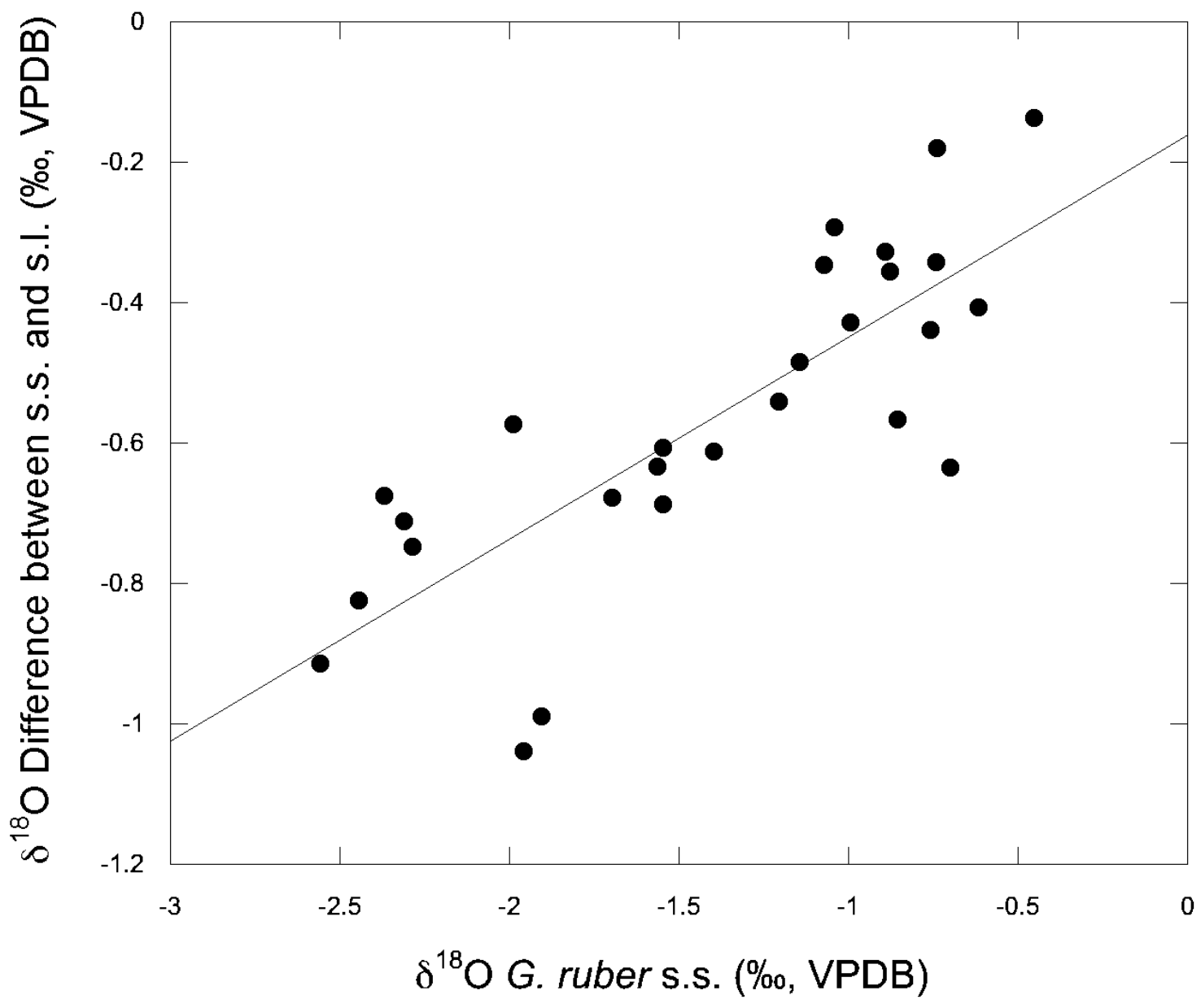




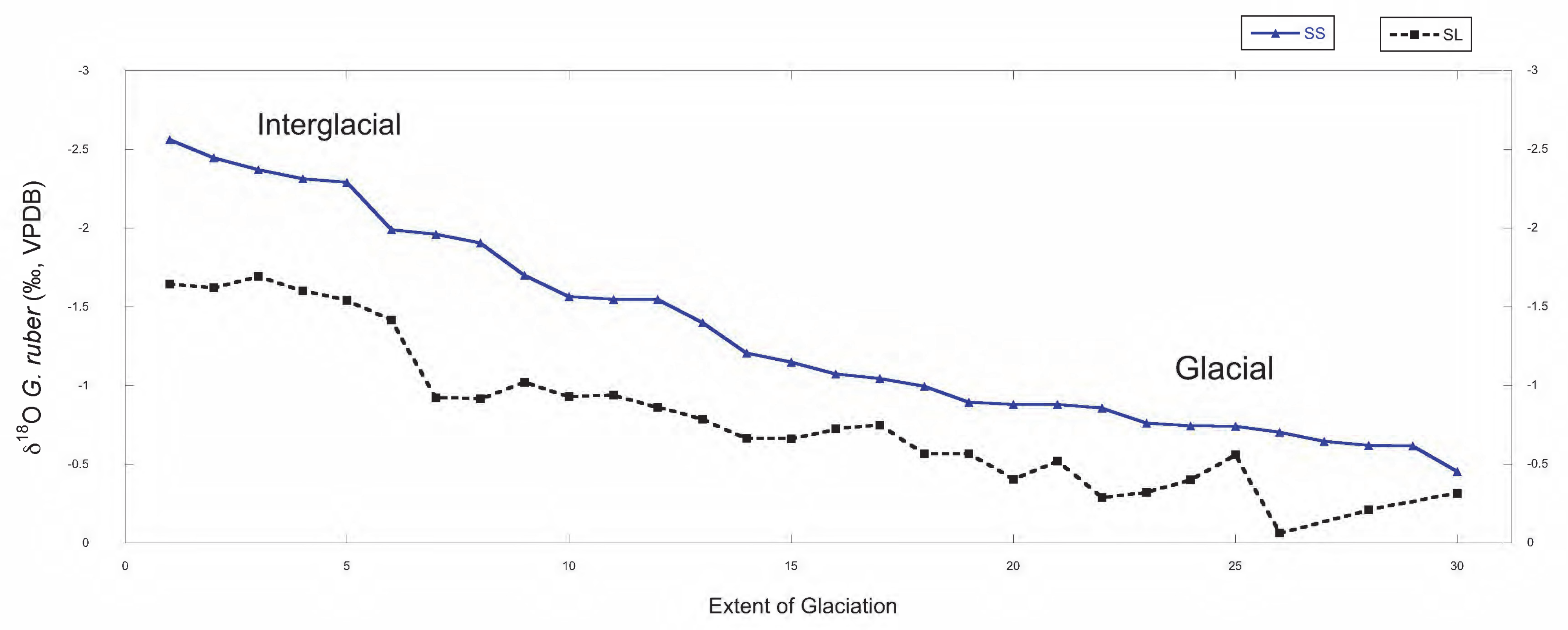

